Revista Verde de Agroecologia e Desenvolvimento Sustentável

http://www.gvaa.com.br/revista/index.php/RVADS

ARTIGO CIENTÍFICO

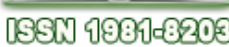

DOI: http://dx.doi.org/10.18378/rvads.v10i4.3824

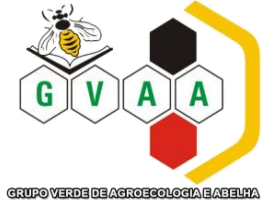

\title{
Produção de mudas de maracujazeiro amarelo com diferentes tipos de enxertia e uso da câmara úmida
}

\section{Seedling production of yellow passionfruit with different types of graft and use of humid chamber}

\author{
Roseano Medeiros da Silva ${ }^{1}$, Ana Verônica Menezes de Aguiar ${ }^{1}$, Vender Mendonça ${ }^{2}$, Eudes de Almeida Cardoso ${ }^{2}$, Kaio \\ Gráculo Vieira Garcia ${ }^{3}$
}

\begin{abstract}
Resumo: O objetivo deste trabalho foi avaliar a combinação de três formas de realização da enxertia pelo método de garfagem e uso da proteção da enxertia com câmara úmida na a produção de mudas de maracujazeiro. O delineamento experimental adotado foi o de blocos ao acaso em esquema fatorial $(3 \times 2)$, com seis repetições, sendo cada parcela constituída de nove plantas, os fatores formaram as combinações de três formas de realização da enxertia pelo método de garfagem (fenda cheia, fenda lateral e fenda simples) e utilização e não do uso da proteção da enxertia com câmara úmida. Para produção das mudas dos portaenxertos e enxertos foram utilizadas sementes das cultivares FB 100 e redondo amarelo respectivamente. As enxertias foram realizadas aos 70 dias após a semeadura. Aos 21 dias após as enxertias foi avaliada a porcentagem de pegamento e a cada 14 dias após a enxertia avaliou-se a sobrevivência de plantas que permaneceram vivas, aos 56 dias avaliou-se o número de folhas, diâmetro do enxerto e portaenxerto, altura da planta e massa seca da parte aérea. Os tipos de enxertias por fenda cheia e fenda lateral, associadas ao uso da proteção com câmara úmida promoveram os melhores índices de pegamento e sobrevivência das mudas de maracujazeiro amarelo, porém o uso proteção promoveu um decréscimo no crescimento das plantas.
\end{abstract}

Palavras-chaves: Passiflora edulis Sims, propagação, enxertia.

\begin{abstract}
The objective at this search was to evaluate the combination of three forms of grafting by the grafting method and grafting using protection with damp in the production of passion fruit seedlings camera. The experimental design was randomized blocks in a $3 \times 2$ factorial arrangement with six replications, each plot were nine plants, the factors formed the combinations of three embodiments by the grafting method (cleft, crack and lateral simple) and crack use and not use protection grafting with moist chamber. Seedlings rootstocks production and grafts seeds of cultivars were used respectively FB 100 and round yellow respectively. The grafts were performed at 70 days after sowing. At 21 days after grafting was evaluated the percentage of fruit set and every 14 days after grafting, we evaluated the plants survival that remained alive, at 56 days assessed the number of leaves, rootstock and graft diameter, plant height and dry weight of shoots. The types of grafts for full and side slit slit associated with the use of protective moist chamber provided better rates of survival and fixation of passion fruit seedlings, however, the use protection caused a decrease in plant growth.
\end{abstract}

Key words: Passiflora edulis Sims, propagation, grafting.

\footnotetext{
*Autor para correspondência

Recebido para publicação em 01/10/2015; aprovado em 30/11/2015

${ }^{1}$ Eng. Agr., Doutorando(a) (CAPES) do Programa de Pós-Graduação em Fitotecnia da UFERSA. Mossoró - RN. E-mail: medeiros_ufersa @ hotmail.com; ana_aguiar_@live.com

${ }^{2}$ Prof. D. Sc. do Depto. de Ciências Vegetais da UFERSA, Campus de Mossoró. Mossoró - RN. E-mail: vander@ufersa.edu.br; eudes@ufersa.edu.br

${ }^{3}$ Eng. Agr., Mestrando (CAPES) em Solos e Nutrição de Plantas, UFC - CE. E-mail : kaiovieira88@hotmail.com
} 


\section{INTRODUÇÃO}

O maracujazeiro é uma cultura que vem se destacando como uma das principais frutíferas cultivadas no Brasil, com destaque de produção para os estados da Bahia, Ceará e Minas Gerais. Apesar de o Brasil ser considerado o maior produtor mundial, não esta entre os maiores exportadores, pois o seu consumo interno é maior que sua produção.

A propagação em escala comercial é realizada por via sexual, no entanto a propagação por enxertia poderá ter grande importância para a cultura, na solução de problemas relativos a pragas e doenças. A enxertia no maracujazeiro amarelo é uma técnica recomendada por vários autores (NOGUEIRA FILHO et al., 2005; CHAVES et al., 2004; LIMA; CUNHA, 2004; SILVA et al., 2005; SILVA et al., 2011). Uma das vantagens do uso da enxertia é o controle de fitopatógenos através do uso adequado de portaenxerto. Para Ruggiero; Oliveira (1998), a utilização da enxertia na cultura do maracujazeiro tem como principais vantagens a resistência à morte prematura das plantas, melhoria na qualidade dos frutos e aumento da longevidade da cultura.

Segundo Ruggiero (1991), os tipos de enxertia de garfagem mais usados para o maracujazeiro são a fenda cheia e o inglês simples, com pegamento superior a $90 \%$, em ambos os processos. No entanto, Pace (1984) testando quatro métodos de enxertia em maracujazeiro amarelo, concluiu que a garfagem do tipo fenda lateral foi mais eficiente, com $89 \%$ de pegamento.

Quanto a proteção da enxertia, alguns autores como Hartmann et al., (1990); Simão, (1998) e Cavichioli et al., (2009) descrevem que, o uso da proteção do enxerto com saquinhos de polietileno transparente, tem a finalidade de proteger e formar uma câmara úmida que impede a troca de umidade entre o ambiente interno e o externo, mantendo assim, a umidade da região enxertada e favorecendo o processo de fixação e soldadura da enxertia.

Nesse sentido, o objetivo deste trabalho foi avaliar diferentes tipos de enxertia e uso da proteção com câmara úmida na produção de mudas de maracujazeiro amarelo.

\section{MATERIAL E MÉTODOS}

$\mathrm{O}$ experimento foi conduzido no período de junho a novembro de 2011 no viveiro de produção de mudas (50\% de interceptação de entrada de luz) do Departamento de Ciências Vegetais da Universidade Federal Rural do Semi-Árido UFERSA, Mossoró - RN. O delineamento experimental adotado foi o em blocos ao acaso com seis repetições, sendo cada parcela constituída de nove plantas em um esquema fatorial $3 \times 2$, os fatores formaram às combinações de três formas de realização da enxertia pelo método de garfagem (fenda cheia, fenda lateral e fenda simples) e utilização e não do uso da proteção com câmara úmida.

Para produção das mudas dos portaenxertos e enxertos de maracujazeiros foram utilizadas sementes da cultivar FB 100 e redondo-amarelo da marca comercial Topseed $^{\circledR}$ respectivamente. A semeadura foi realizada no dia 28 de junho de 2011 em sacos de polietileno preto com capacidade para 1 litro de volume, sendo o substrato composto da mistura de terra de barranco (75\%) e esterco bovino curtido (25\%), acrescido de uma mistura de $500 \mathrm{~g} \mathrm{~m} 3$ de uma formulação comercial de N-P-K (4-14-8).

Aos 70 dias após a semeadura, quando as plantas se apresentavam em fase de irem para o campo foram realizadas as enxertias, segundo a disposição do delineamento experimental. Os portaenxertos foram decepados com tesoura de poda abaixo do primeiro par de folhas, a uma altura média de $10 \mathrm{~cm}$ a partir do colo. Para a realização das enxertias utilizou-se uma lâmina tipo "bisturi" e para proteção e fixação da enxertia foi utilizado à fita biodegradável. Para os tratamentos que correspondiam ao uso da proteção por câmara úmida foi utilizados sacos plásticos transparente de $4 \times 22 \mathrm{~cm}$ sem o amarrio da base.

O sistema de irrigação adotado foi microasperssão, controlado no interior do viveiro por timer, programado para duas vezes ao dia pela manhã e a tarde por $45 \mathrm{~min}$.

As médias mensais de temperatura e umidade relativa do ar foram interpretadas com base nos dados dos mapas agroclimáticos do INMET para a região de Mossoró para a época de condução do experimento (Figura 1).

Figura 1. Dados médios mensais de temperatura máxima $-\mathrm{T}^{\circ} \mathrm{C}_{\max }(\square)$, média $-\mathrm{T}^{\circ} \mathrm{C}_{\text {med }}(\square)$, mínima $-\mathrm{T}^{\circ} \mathrm{C}_{\min }(\square) \mathrm{e}$ umidade relativa - UR \% ( - ) para região de Mossoró - RN no período da condução do experimento com base nos mapas agroclimáticos do INMET (2011).

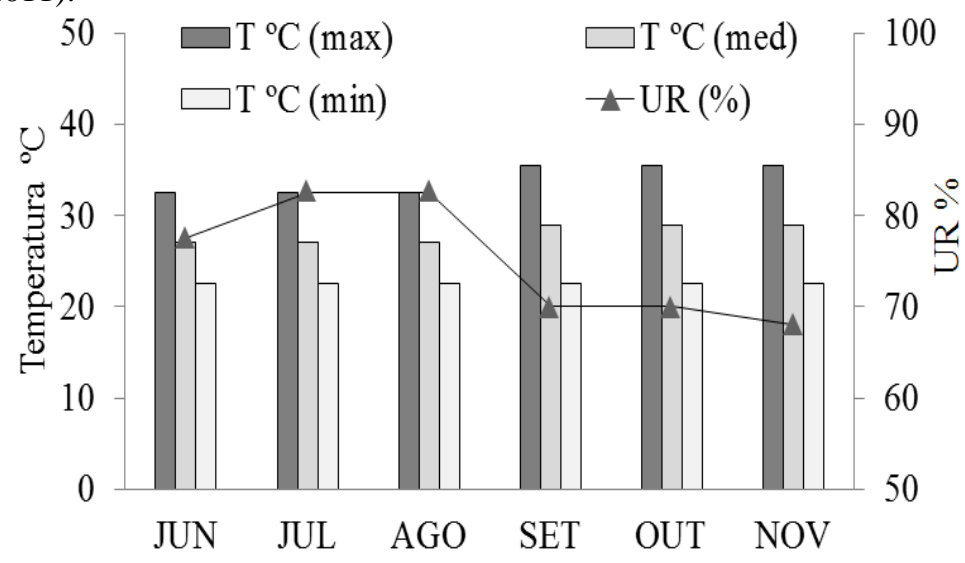

Observou-se o pegamento das enxertias a cada sete dias, considerando como parâmetro a emissão de brotações, assim retirando-se a proteção por câmara úmida. Aos 21 dias após as enxertias, quando se verificou a estabilização do pegamento, foram retiradas todas as proteções ainda existentes e avaliado a porcentagem de pegamento para todos os tratamentos. Aos 28, 42 e 56 dias após a enxertia foi avaliado a sobrevivência em porcentagem de plantas que 
permaneceram vivas. Aos 56 dias após a enxertia avaliou-se número de folhas, diâmetro do enxerto e portaenxerto na altura da enxertia medido com auxilio de paquímetro digital com precisão de duas casas decimais, altura da planta medindo-se da base ate o meristema apical e massa seca da parte aérea obtida em estufa de circulação forçada aos $65^{\circ} \mathrm{C}$ por 48 horas.

Os dados de porcentagem de pegamento e sobrevivência foram transformados em Arc.Sen $\sqrt{X}(\%) / 100$ para fins de análise estatística. Os resultados obtidos foram submetidos a analise de variância e as medias comparadas pelo teste de Tukey a $5 \%$ de probabilidade.

\section{RESULTADOS E DISCUSSÃO}

Houve diferença significativa para os diferentes tipos de enxertia e uso da proteção com câmara úmida para a maioria das características avaliadas. Verifica-se que houve interação significativa para porcentagem de pegamento aos 21 dias após a enxertia.

Os tipos de enxertia que apresentaram as maiores porcentagem de pegamento aos 21 dias foram fenda cheia e fenda lateral. Não houve influência do uso da proteção com câmara úmida para as enxertias tipo fenda cheia e lateral, portanto há uma diminuição da taxa de pegamento quando não se utiliza a proteção no tipo fenda simples (Tabela 1).

Tabela 1 - Médias da porcentagem de pegamento de mudas de maracujazeiro em função do tipo de enxertia e uso da proteção com câmara úmida. Mossoró - RN, 2012.

\begin{tabular}{ccc}
\hline & & Pegamento $(\%)^{2}-21$ dias \\
Tipos de enxertia1 & Proteção da enxertia & Sem \\
\cline { 2 - 3 } & Fenda cheia & $94,45 \mathrm{aA}$ \\
Fenda lateral & $94,45 \mathrm{aA}$ & $88,89 \mathrm{aA}$ \\
Fenda simples & $94,45 \mathrm{aA}$ & $11,12 \mathrm{bB}$ \\
\hline 1- Médias seguidas pela mesma letra, maiúscula na linha e minúscula na coluna, não diferem entre si pelo teste de Tukey ao nível de 5\% de probabilidade. 2 \\
- Os dados de porcentagem foram transformados em Arc.Sen $\sqrt{\mathrm{x}} / 100$.
\end{tabular}

Esses resultados concordam em partes com os obtidos por Lima (2009), que observando o efeito de diferentes métodos de enxertia e ambiente na otimização de métodos de propagação do maracujazeiro por estaquia e enxertia, observou que não houve diferença para os tipos de enxertia por garfagem fenda cheia e lateral como também não sofreram interferência do ambiente interno aberto e fechado para o índice de porcentagem de pegamento. Chaves et al. (2004), estudando a enxertia de maracujazeiro azedo em estacas herbáceas enraizadas de espécies de passifloras nativas também não observaram efeito significativo da proteção do enxerto com saco de plástico no índice de pegamento da enxertia. Santos et al. (2011), trabalhando com tipos de enxertia em diferentes idades de plântulas de maracujazeiro não observaram diferenças para os tipos de enxertia por garfagem em fenda cheia e fenda simples. Isso pode estar relacionado à idade da enxertia, pois os mesmos autores afirmam que a antecipação da enxertia para 15 dias após a emergência das plântulas facilita uma melhor fixação e soldadura do material. Roncatto et al. (2011), estudando modalidade de enxertia para o maracujazeiro não observaram diferença para os tipos de enxertia por garfagem fenda cheia e lateral quando verificaram a porcentagem de pegamento aos 20 dias após a realização, portanto ao passar do tempo a enxertia por fenda cheia se sobressaiu.

O menor índice de pegamento encontrado pelo tipo fenda simples também pode estar relacionado a esse tipo de enxertia apresentar como inconveniência a dificuldade de fixação por apresentar uma menor superfície de contato, como descrito por Nachitigal et al. (2005), isso associado ao não uso da proteção provocar um ressecamento maior da área enxertada, para que isso não ocorra é necessário se manter um alto teor de umidade no local da enxertia. Segundo Corrêa et al. (2010), o uso da proteção com câmara úmida tem por finalidade impedir a troca de umidade entre ambiente interno e o externo, mantendo assim a umidade do local da enxertia.

Quanto aos tipos de enxertia, Lima et al. (1999), avaliando portaenxertos e tipos de enxertia para o maracujazeiro amarelo, não observaram diferença significativa entre os tipos fenda cheia e fenda simples. Já Roncatto et al. (2011), observaram que a enxertia por garfagem em fenda cheia mostrou-se mais adequada para o maracujazeiro, obtendo $98 \%$ de pegamento contra $70 \%$ por fenda lateral, porém Pace (1984) testando quatro métodos de enxertia em maracujazeiro amarelo, concluiu que a garfagem do tipo fenda lateral foi mais eficiente, com $89 \%$ de pegamento. Porém, Lima (2005), descreve que o método de enxertia do tipo fenda cheia é o mais usado, com pegamento de até 90\%. Chaves et al. (2004) e Silva et al. (2005) conseguiram percentagem de $98 \%$ de pegamento, utilizando enxertia por fenda cheia em portaenxerto por estaca. Menezes et al. (1994) afirma que, quando se trabalha com enxertia intraespecífica em maracujazeiro, os resultados são mais promissores, alcançando até $100 \%$ de pegamento, pois existe maior afinidade quando a enxertia é feita sobre a própria espécie.

Os tipos de enxertia por fenda cheia e fenda lateral apresentaram os maiores índices de sobrevivência e permaneceu em $86,12 \%$ e $91,67 \%$ respectivamente para os 28, 42 e 56 dias após a enxertia (Figura 2A).

$\mathrm{O}$ baixo índice de sobrevivência das mudas enxertadas por fenda simples podem estar diretamente ligada ao baixo índice de pegamento influenciado pelo não uso da câmara úmida. Nogueira Filho et al. (2011), estudando a enxertia hipocotiledonar no maracujazeiro observou que a percentagem de enxertos pegos permaneceu a mesma durante 60 dias de observações para a enxertia do P. edulis Sims sobre ele mesmo. 
Figura 2. Avaliação de tipos de enxertia (A) e influência do uso da proteção da enxertia (B) quanto à porcentagem de sobrevivência aos 28, 42 e 56 dias após a realização. Mossoró - RN, 2012.

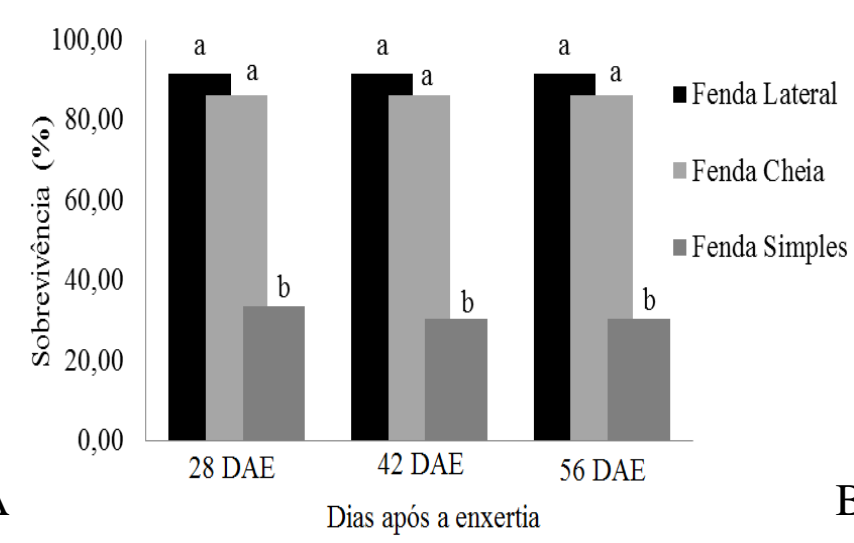

As plantas provenientes de enxertos protegidos com câmara úmida apresentaram a maior média de porcentagem de sobrevivência $(79,63 \%)$ para os 28,42 e 56 dias após a enxertia (Figura 2B). Corrêa et al. (2010), trabalhando com uso da câmara úmida em enxertia convencional de maracujazeiro amarelo, observaram que o uso da proteção da enxertia com câmara úmida favorece a sobrevivência dos enxertos.

Cardoso et al. (2010), avaliando a eficiência de tipos de proteção na substituição de copa por garfagem lateral no cajueiro comum, observaram que o uso da proteção favorece

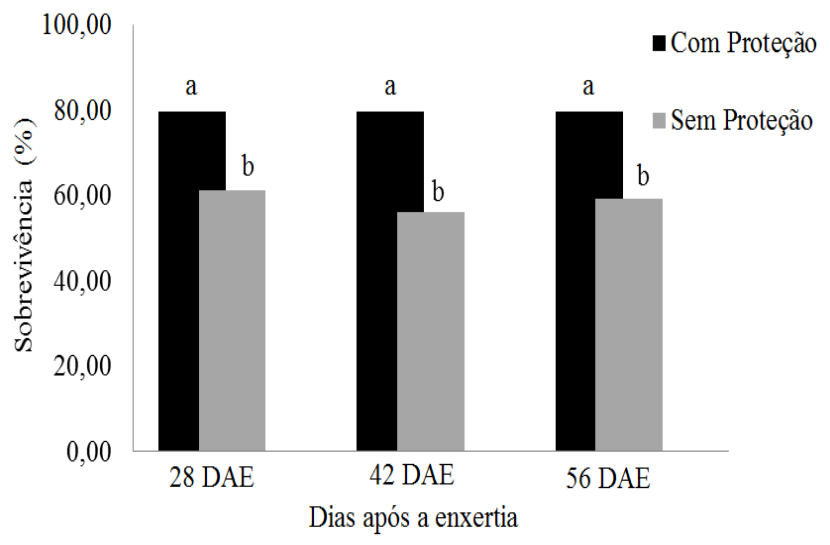

tanto a porcentagem de pegamento como a sobrevivência dos enxertos.

O diâmetro do portaenxerto para os tipos de enxertia por fenda cheia e fenda lateral apresentaram o maior crescimento $(5,33 \mathrm{~mm})$ e $(5,34 \mathrm{~mm})$ respectivamente (Figura 3A).

Verificou-se que o uso da proteção com câmara promoveu um decréscimo em relação à altura da planta e diâmetro do portaenxerto e consequentemente diminui o peso da matéria seca da parte aérea (Figura 3B).

Figura 3. (A) Diâmetro do portaenxerto em função dos tipos de enxertia e (B) influência do uso da proteção da enxertia sobre a altura das plantas - ALP $(\mathrm{cm})$, diâmetro do portaenxerto - DPE (mm) e matéria seca da parte aérea - MSPA (g) (B) aos 56 dias após a enxertia. Mossoró - RN, 2012.

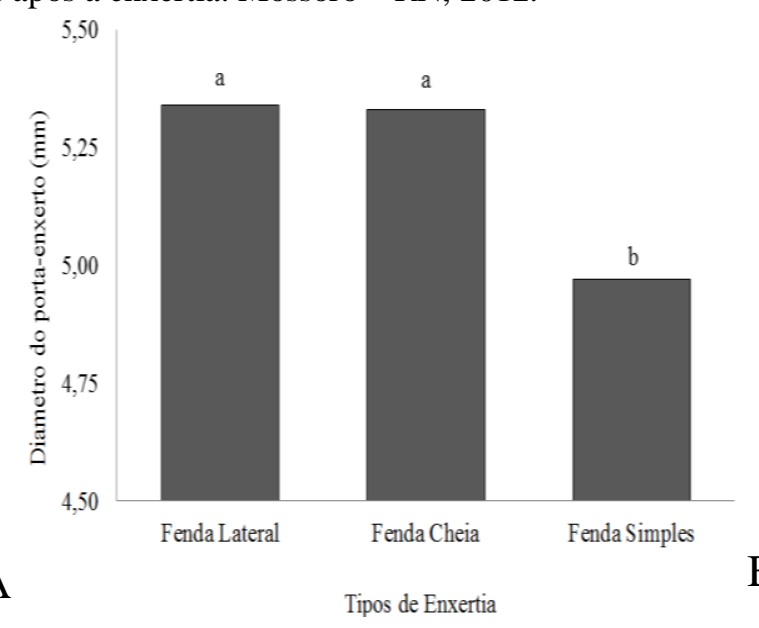

Corrêa et al. (2010), trabalhando com uso da câmara úmida em enxertia convencional de maracujazeiro amarelo, também observaram que o uso da câmara úmida prejudicou o crescimento das plantas, porém não houve interferência do uso da câmara sobre o diâmetro do portaenxerto e matéria seca da parte aérea. Já Cavichioli et al. (2009), estudando o uso da câmara úmida em enxertia hipocotiledonar em maracujazeiro amarelo, observaram que o uso da câmara úmida provocou um decréscimo sobre o crescimento do diâmetro do portaenxerto e o peso da matéria seca da parte aérea.

Jacomino et al. (2000), avaliando métodos de proteção da enxertia para plantas frutíferas, observaram que para a nogueira macadâmia o uso de saquinhos de polietileno prejudicou o diâmetro e comprimento das brotações. $\mathrm{O}$ uso da

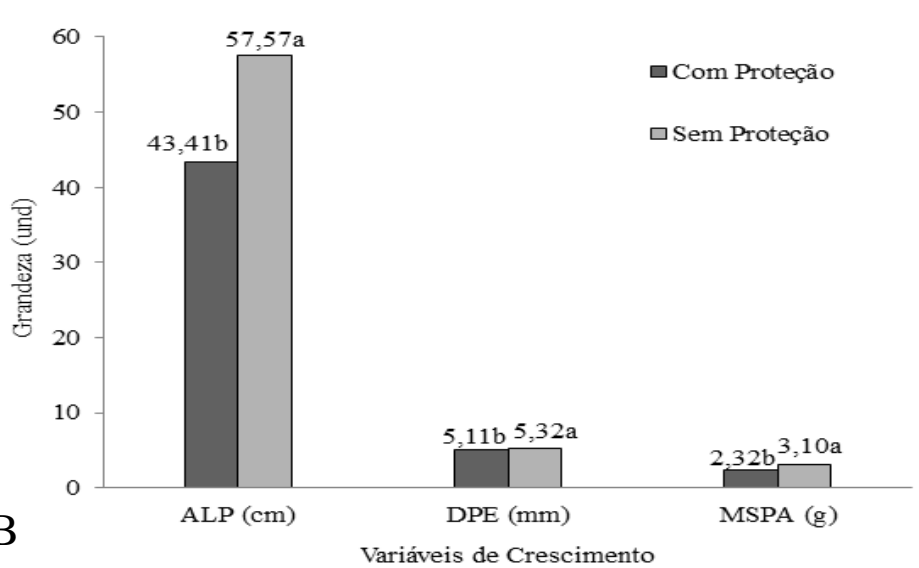

proteção da enxertia prejudica o desenvolvimento apical da planta, para isso recomenda-se o uso de sacos maiores, que não interfiram no desenvolvimento da gema apical ou a redução do tempo da permanência do saco plástico. Para Hartmann et al. (1990), o rápido pegamento da enxertia é fundamental para o sucesso da operação, pois diminui o período em que o enxerto fica exposto aos riscos da desidratação.

Com base nas variáveis analisadas, os melhores tipos de enxertia para o maracujazeiro amarelo são por garfagem em fenda cheia e lateral. Para um melhor índice de pegamento das enxertias é fundamental o uso da proteção com câmara úmida. Porém, o uso da câmara úmida promoveu um decréscimo no crescimento das plantas, sendo assim, 
necessário um menor tempo possível de permanência da proteção sobre as plantas.

\section{CONCLUSÕES}

As enxertias de garfagem tipo fenda cheia e lateral associadas ao uso de proteção por câmara úmida promoveram os melhores índices de pegamento e sobrevivência para o maracujazeiro amarelo.

\section{REFERÊNCIAS BIBLIOGRÁFICAS}

CARDOSO, E. de A.; SILVA, R. M. da.; MARACAJÁ, P. B.; OLIVEIRA, W. P. R. de.; SOUSA, R. P. de. Eficiência de tipos de proteção na substituição de copa por garfagem lateral no cajueiro comum. Revista Verde de Agroecologia e Desenvolvimento Sustentável, Mossoró RN, v. 05, n.02, p.153-157, 2010.

CAVICHIOLI, J. C.; CORRÊAA, L. de S.; BOLIANI, A. C.; OLIVEIRA, J. C. de. Uso de câmara úmida em enxertia hipocotiledonar de maracujazeiro-amarelo sobre três porta-enxertos. Revista Brasileira de Fruticultura, Jaboticabal - SP, v.31, n.2, p.532-538, 2009.

CHAVES, R. da C.; JUNQUEIRA, N. T. V.; MANICA, I.; PEIXOTO, J. R.; PEREIRA, A. V.; FIALHO, J. de F. Enxertia de maracujazeiro-azedo em estacas herbáceas enraizadas de espécies de passifloras nativas. Revista Brasileira de Fruticultura, Jaboticabal - SP, v.26, n.1, p.120-123, 2004.

CORRÊA, L. de S.; CAVICHIOLI, J. C.; OLIVEIRA, J. C. de.; BOLIANI, A. C. Uso de câmara úmida em exxertia convencional de maracujazeiro-amarelo sobre três portaenxertos. Revista Brasileira de Fruticultura, Jaboticabal SP, v.32, n.2, p.591-598, 2010.

INMET - Instituto Nacional de Meteorologia. Dados Agroclimatológico: Estações Meteorológicas Convencionais do INMET. Disponível em: http://www.inmet.gov.br/climatologia/bol_agro/mapas.ph p. Acesso em: 21 de agosto de 2012.

JACOMINO, A. P.; MINAMI, K.; KLUGE, R. A.; KISHIMO, A. Métodos de proteção de enxerto na produção de mudas de mangueira, abacateiro e nogueiramacadâmia. Pesquisa Agropecuária Brasileira, Brasília, v.35, n.10, p.1985-1990, 2000.

LIMA, A. de A. Aspectos fitotécnicos: desafios da pesquisa. In: FALEIRO, F. G.; JUNQUEIRA, N. T. V.; BRAGA, M. F. (Ed.). Maracujá: germoplasma e melhoramento genético. Planaltina Distrito Federal: Embrapa Cerrados, 2005. $670 \mathrm{p}$.

LIMA, A. de A.; CALDAS, R. C.; CUNHA, M. A. P.; SANTOS FILHO, H. P. Avaliação de porta-enxertos e tipos de enxertia para o maracujá-amarelo. Revista Brasileira de Fruticultura, Jaboticabal - SP, v.21, n.3, p.318-321, 1999.

LIMA, A. de A.; CUNHA, M. A. P. Maracujá: Produção e qualidade na passicultura. Cruz das Almas: EMBRAPA MANDIOCA E FRUTICULTURA, 2004. 396p.

LIMA, C. A. Otimização de métodos de propagação de maracujazeiro via estaquia e enxertia. 2009. $105 f$. Dissertação (Mestrado) - Faculdade de Agronomia e Medicina Veterinária, Universidade de Brasília, Brasília. 2009.
MENEZES, J. M. T.; OLIVEIRA, J. C.; RUGGIERO, C.; BANZATTO, D. A. Avaliação da taxa de pegamento de enxertos de maracujá-amarelo sobre espécies tolerantes à morte prematura de plantas. Científica, São Paulo - SP, v.22, n.1, p.95-104, 1994.

NACTHIGAL, J. C.; FACHINELLO, J. C.; HOFFMANN, A. Propagação vegetativa por enxertia. In: FACHINELLO, J. C.; HOFFMANN, A.; NACHTIGAL, J. C. Propagação de plantas frutíferas. Brasília - DF: Embrapa Informação Tecnológica, 2005, 221p.

NOGUEIRA FILHO, G. C.; RONCATTO, G.; RUGGIEIRO, C.; OLIVEIRA, J. C. de; MALHEIROS, E. B. Propagação vegetativa do maracujazeiro-conquista de novas adesões. In: FALEIRO, F. G.; JUNQUEIRA, N. T. V.; BRAGA, M. F. (Ed.). Maracujá: germoplasma e melhoramento genético. Planaltina: Embrapa Cerrados, 2005. p.341-358.

NOGUEIRA FILHO, G. C.; RONCATTO, G.; RUGGIERO, C.; OLIVEIRA, J. C. de.; MALHEIROS, E. B. Produção de mudas de maracujazeiro-amarelo por enxertia hipocotiledonar sobre sete espécies de passifloras. Revista Brasileira de Fruticultura, Jaboticabal - SP, v.33, n.1, p.237-245, 2011.

PACE, C. A. M. Comparação de quatro métodos de enxertia para o maracujazeiro amarelo Passiflora edulis $f$. flavicarpa Deg. In: CONGRESSO BRASILEIRO DE FRUTICULTURA, 7, 1983, Florianópolis. Anais... Florianópolis, EMPASC/Sociedade Brasileira de Fruticultura, 1984. p.983-988.

RONCATTO, G.; LENZA, J. B.; VALENTE, J. P. Modalidades de enxertia para maracujazeiro: avaliação preliminar nas condições da depressão cuiabana. Revista Brasileira de Fruticultura, Jaboticabal - SP, v.33, n.1, p.316-320, 2011.

RUGGIERO, C. Enxertia do maracujazeiro. In: SÃO JOSÉ, A. R. (Ed.). A cultura do maracujá no Brasil. Jaboticabal: FUNEP, 1991. p.43-59.

RUGGIERO, C.; OLIVEIRA, J. C. de. Enxertia do maracujazeiro. In: SIMPÓSIO BRASILEIRO SOBRE A CULTURA DO MARACUJAZEIRO, 5., 1998. Anais... Jaboticabal: FUNEP, 1998. p.70-92.

SANTOS, V. A. dos.; RAMOS, J. D.; OLIVEIRA, M. C. de.; SILVA, E. A. da. Tipos de enxertia em diferentes idades de plantas de maracujazeiro. Revista Brasileira de Fruticultura. Jaboticabal - SP, v.33, n.4, p.1359-1363, 2011.

SILVA, F. M.; CORREA, L. de S.; BOLIANI, A. C.; SANTOS, P. C. dos. Enxertia de mesa de Passiflora edulis Sims f. flavicarpa Deg. sobre Passiflora alata Curtis, em ambiente de nebulização intermitente. Revista Brasileira de Fruticultura, Jaboticabal - SP, v.27, n.1, p.98-101, 2005.

SILVA, R. M. da.; AGUIAR, A. V. M. de.; CARDOSO. E. de A.; OLIVEIRA, L. A. de A.; LIMA, J. G. A. Germinação e crescimento inicial de mudas de cinco espécies de maracujá (Passiflora spp.) visando obtenção de porta-enxerto. Revista Verde de Agroecologia e Desenvolvimento Sustentável, Mossoró - RN, v. 6, n.1, p. 131 - 135. 2011.

SIMÃO, S. Tratado de fruticultura. Piracicaba: FEALQ, 1998. $760 \mathrm{p}$. 